\title{
Genetic risk score to predict biochemical recurrence after radical prostatectomy in prostate cancer: prospective cohort study
}

\author{
Jong Jin Oh ${ }^{1}$, Seunghyun Park ${ }^{2,3}$, Sang Eun Lee ${ }^{1}$, Sung Kyu Hong ${ }^{1}$, Sangchul Lee ${ }^{1}$, \\ Tae Jin Kim ${ }^{1}$, In Jae Lee ${ }^{1}$, Jin-Nyoung Ho ${ }^{1,4}$, Sungroh Yoon ${ }^{2}$ and Seok-Soo Byun ${ }^{1}$ \\ ${ }^{1}$ Department of Urology, Seoul National University College of Medicine, Seoul National University Bundang Hospital, \\ Seongnam, Korea \\ ${ }^{2}$ Department of Electrical and Computer Engineering, Seoul National University, Seoul, Korea \\ ${ }^{3}$ School of Electrical Engineering, Korea University, Seoul, Korea \\ ${ }^{4}$ Biomedical Research Institute, Seoul National University Bundang Hospital, Seongnam, Korea \\ Correspondence to: Seok-Soo Byun, email: ssbyun@snubh.org
}

Keywords: prostate cancer, genetic risk score, recurrence, predictive value

Received: April 12, 2017 Accepted: May 07, $2017 \quad$ Published: May 26, 2017

Copyright: Oh et al. This is an open-access article distributed under the terms of the Creative Commons Attribution License 3.0 (CC BY 3.0 ), which permits unrestricted use, distribution, and reproduction in any medium, provided the original author and source are credited.

\section{ABSTRACT}

Purpose: To investigate the genetic risk score (GRS) from a large-scale exomewide association study as a tool of prediction for biochemical recurrence (BCR) after radical prostatectomy $(\mathrm{RP})$ in prostate cancer $(\mathrm{PCa})$.

Results: The 16 SNPs were selected as significant predictors of BCR. The GRS in men experiencing BCR was $\mathbf{- 1 . 2 1}$, significantly higher than in non-BCR patients $(-2.43)$ $(p<0.001)$. The 10 -year BCR-free survival rate was $46.3 \%$ vs. $81.8 \%$ in the highversus low GRS group, respectively $(p<0.001)$. The GRS was a significant factor after adjusting for other variables in Cox proportional hazard models (HR:1.630, $p<0.001$ ). The predictive ability of the multivariate model without GRS was $84.4 \%$, increased significantly to $88.0 \%$ when GRS was included $(p=0.0026)$.

Materials and Methods: Total 912 PCa patients were enrolled who had received RP and genotype analysis using Exome chip (HumanExome BeadChip). Genetic results were obtained by the methods of logistic regression analysis which measured the odds ratio (OR) to BCR. The GRS was calculated by the sum of each weighted-risk allele count multiplied by the natural logarithm of the respective ORs. Survival analyses were performed using the GRS. We compared the accuracy of separate multivariate models incorporating clinicopathological factors that either included or excluded the GRS.

Conclusions: GRS had additional predictive gain of BCR after RP in PCa. The addition of personally calculated GRS significantly increased the BCR prediction rate. After validation of these results, GRS of BCR could be potential biomarker to predict clinical outcomes.

\section{INTRODUCTION}

Prostate cancer $(\mathrm{PCa})$ is the most common malignant cancer affecting adult males in the United States, it was measured for $15 \%$ of new cancer and $7 \%$ of total male cancer related deaths in 2012 [1]. The radical prostatectomy (RP) is the gold standard surgical procedure for localized PCa [2]. Although localized PCa had good 10 year biochemical recurrence (BCR) outcomes which reported 73-99\%, some
PCa after RP will recurred [3, 4]. Five years after RP, 15\% of men experience this biochemical recurrence (BCR), while $20 \%$ to $40 \%$ of men exhibit BCR 10 years after RP $[5,6]$. Previous reports showed important predictors of BCR were serum prostate specific antigen (PSA), Gleason score, pathological stage such as extracapsular extentsion (ECE) or seminal vesicle invasion (SVI) and positive surgical margins (PSM). However, predictive accuracy of BCR was limited in these studies. Accordingly, substantial efforts have been 
made to identify novel prognostic markers such as genetic markers to predict BCR after surgical treatment [3, 7-10].

To date, more than 100 single nucleotide polymorphisms (SNPs) have been associated with $\mathrm{PCa}$ through genome wide association studies (GWAS) [11]. Many new variants had been published, however not many studies showed PCa related risk variants from Asian populations [11-13] And there are few studies investigate PCa related outcomes using GRS such as BCR except. One study for PCa-associated BCR using combination of genetic information was published [14]. One GWAS in China showed several significant SNPs were associated with PCa susceptibility [15]. Although this report illustrated methods for prediction of cancer risk, PCa related clinical parameters were not included. Other Asian study showed that some PCa variants were significantly associated BCR rates after RP [16]. However, this study was limitation about small analyzed SNP numbers and relative small cohorts.

While SNPs can be easily assessed in blood samples, their clinical use to PCa is still challenging due to largescale data from genetic analysis. Therefore, the genetic risk score (GRS) was developed, derived and calculated from multiple PCa risk-associated SNPs that have been shown to improve accuracy of disease prediction [17]. Recently, genetic risk assessment studies have evaluated effectiveness of cumulative GRS for PCa risk [18-20], However, no study has used GRS in a model to predict BCR using a GWAS.

In the present study, we performed GRS analysis to predict BCR via a combined clinical-genetic model from a prospective cohort of 912 Korean PCa patients by using Exome chip.

\section{RESULTS}

Among total patients, 212 patients (23.2\%) experienced BCR during follow-up duration (median 51-month) (Table 1). The BCR patients had higher initial PSA levels, rates of ECE, rates of SVI, rates of PSM and pathological Gleason scores.

The frequency of genotype results according to presence of BCRs were shown in Figure 1. Among the results from 242,186 SNPs, we selected target SNPs with a $p$-value level of $10^{-3}$. Sixteen SNPs (rs4965121, rs1128966, rs1046404, rs1046403, rs781831, rs7009549, rs12871532, rs16964211, rs3133745, rs2071286, rs10853489, rs7439186, rs2144425, rs3935295, rs4745571 and rs17168761) were significantly associated with BCRs in men after RPs (Table 2). The ORs and significance levels are shown in Table 2.

The median GRS value was $-2.10 \pm 1.55$ in the entire cohort (mean -2.26, range-7.19-1.61). The median GRS calculated in men experiencing BCR was $-1.21 \pm$ 1.33 (mean -1.28 , range $-4.54-1.61$ ). This value was significantly higher than the median score in non-BCR patients $(-2.43 \pm 1.49$, mean -2.56 , range $-7.19-0.47$, $p<0.001$ ) (Figure 2).

Survival analysis according to GRS value (-2.0) was shown in Figure 3. The high GRS group had significantly lower BCR-free survival rate than the low GRS group. The 10-year BCR-free survival rate was $46.3 \%$ vs. $81.8 \%$, respectively (log rank test $p<0.001$ ). In subgroup analyses (pathologic T3 and pathologic T2R1 patients), high GRS was also significant factor to BCR outcomes. Among T3 patients $(n=314)$, high GRS patients had

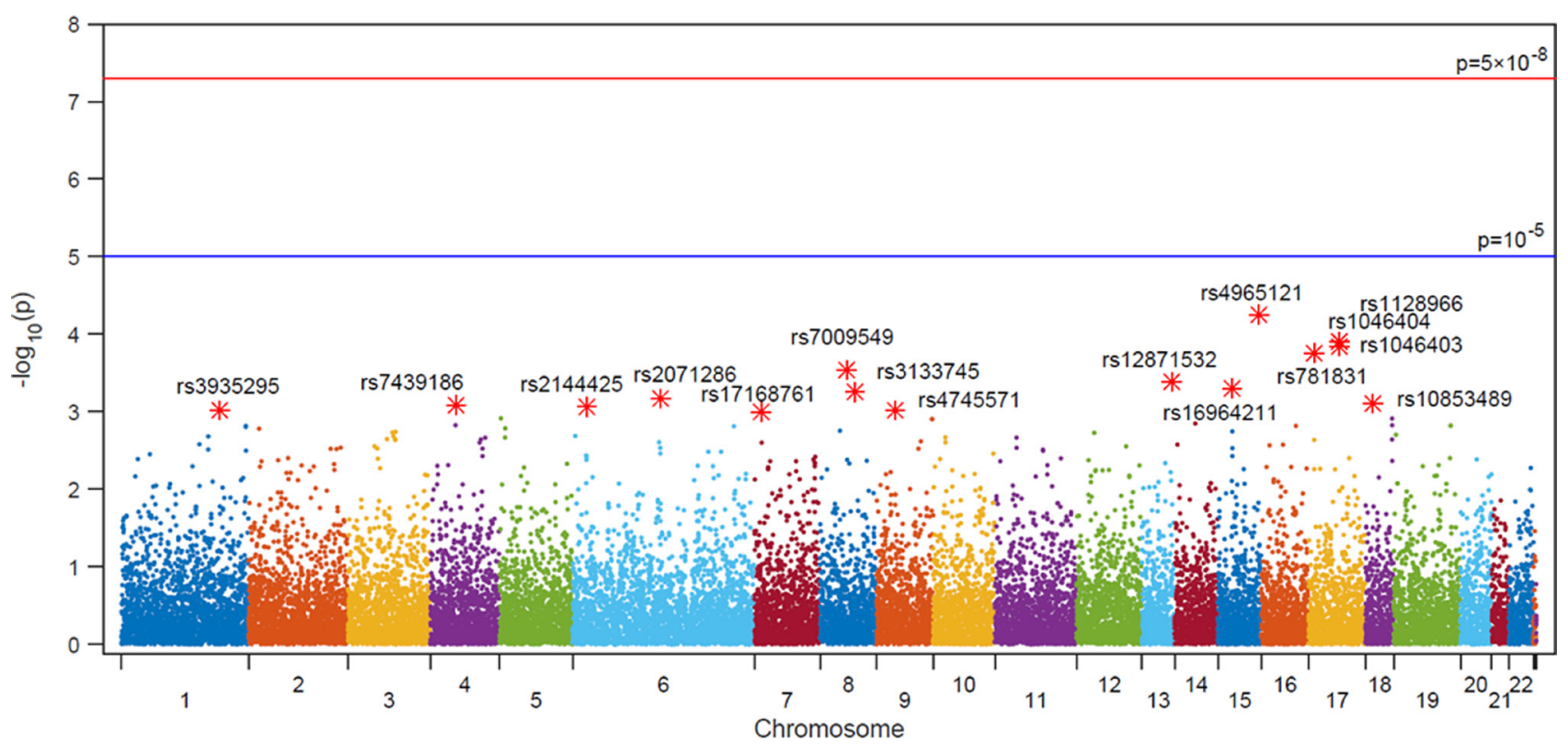

Figure 1: Manhattan plot of SNP association with biochemical recurrence among prostate cancer patients who underwent RP from an analysis of 242,186 single nucleotide polymorphisms using a custom HumanExome BeadChip v1.0 (Illumina Inc.). 
Table 1: Baseline characterisitics according to biochemical recurrence after radial prostatectomy

\begin{tabular}{lcccc}
\hline \multicolumn{1}{c}{ Variables (Mean \pm SD) } & Total (912) & No BCR (700) & BCR (212) & B-value \\
\hline Mean Age & $66.24 \pm 6.63$ & $66.33 \pm 6.72$ & $65.99 \pm 6.37$ & 0.505 \\
Median PSA (ng/ml) & $8.30 \pm 18.92$ & $7.40 \pm 11.32$ & $15.43 \pm 31.27$ & $<0.001$ \\
Mean prostate volume (ml) & $36.91 \pm 16.04$ & $36.44 \pm 16.14$ & $38.46 \pm 20.45$ & 0.185 \\
Extracapsular extension (\%) & $303(33.2)$ & $151(21.6)$ & $152(71.7)$ & $<0.001$ \\
Seminal vesicle invasion (\%) & $94(10.3)$ & $25(3.6)$ & $69(32.5)$ & $<0.001$ \\
Bladder neck invasion (\%) & $40(4.4)$ & $11(1.6)$ & $29(13.7)$ & $<0.001$ \\
Positive surgical margin (\%) & $280(30.7)$ & $151(21.6)$ & $129(60.8)$ & $<0.001$ \\
Pathologic stage (\%) & & & & $<0.001$ \\
pT2 & $598(65.6)$ & $542(77.4)$ & $56(26.4)$ & \\
pT3 & $301(33.0)$ & $154(22.0)$ & $147(69.3)$ & \\
pT4 & $13(1.4)$ & $4(0.6)$ & $9(4.3)$ & \\
Pathology Gleason score (\%) & $62(6.8)$ & $60(8.6)$ & $2(0.9)$ & \\
6 & $712(78.1)$ & $586(83.7)$ & $126(59.4)$ & \\
7 & $42(4.6)$ & $23(3.3)$ & $19(9.0)$ & \\
8 & $96(10.5)$ & $31(4.4)$ & $65(30.7)$ & \\
9 & 0 & 0 & 0 & \\
10 & & &
\end{tabular}

Abbreviations: BCR: biochemical recurrence; SD: standard deviation.

5 year BCR free survival rate was $33.8 \%$, significantly lower in low GRS patients (62.8\%) (Figure 4A). Among T2R1 patients $(n=90), 5$-year BCR-free survival rate was estimated by $87.5 \%$ in high GRS vs. $67.9 \%$ in low GRS $(p=0.001)$ (Figure 4B).
Separate multivariate Cox proportional hazard models were constructed, both including and excluding GRS. Both models included and adjusted variables such as age, initial serum PSA, pathologic Gleason scores, ECE, SVI and PSM after RP, as shown in Table 3. The GRS was

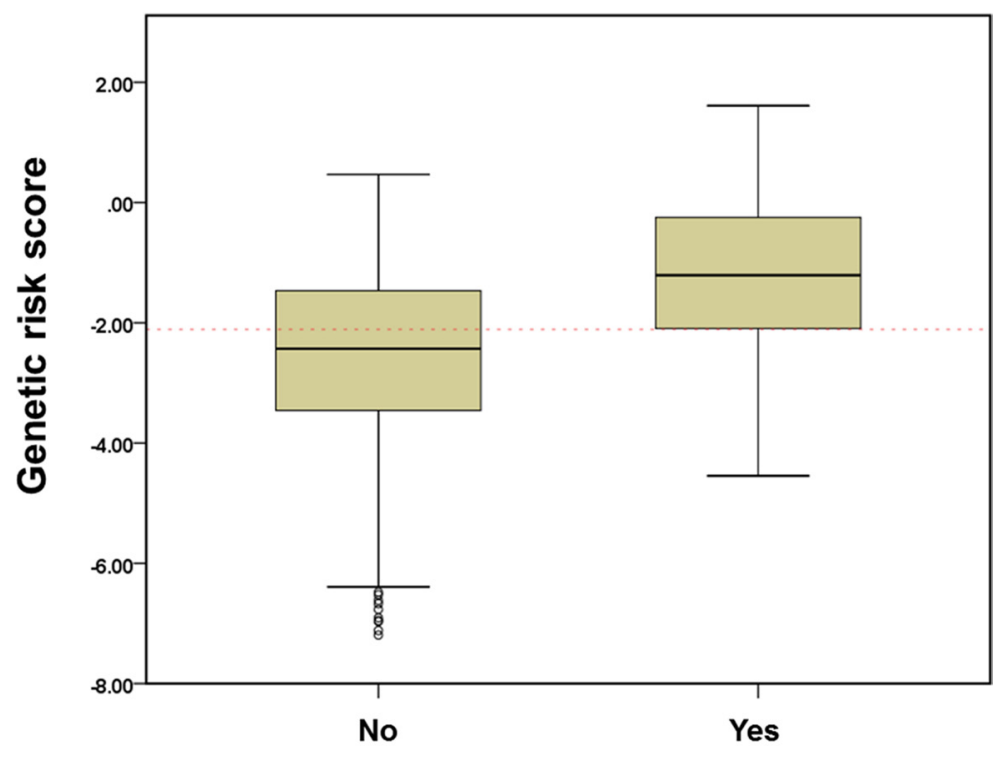

\section{Biochemical recurrence}

Figure 2: The association of genetic risk score (GRS) with biochemical recurrence after radical prostatectomy among prostate cancer patients. GRS was calculated by weighted risk allele count, where risk alleles are weighted by their odds ratios (ORs). $\mathrm{GRS}=$ sum of number of risk alleles $(0,1,2) \times \ln (\mathrm{OR})$. 
Table 2: Logistic regression analysis of exome array with biochemical recurrence after radical prostatectomy

\begin{tabular}{|c|c|c|c|c|c|c|c|}
\hline \multirow[t]{2}{*}{ SNPID } & \multirow[t]{2}{*}{ Chr } & \multirow[t]{2}{*}{ Alleles } & \multirow[t]{2}{*}{ Gene } & \multicolumn{2}{|c|}{$\begin{array}{c}\text { Minor Allele } \\
\text { Frequency }\end{array}$} & \multirow[t]{2}{*}{ OR $(95 \%$ CI $)$} & \multirow[t]{2}{*}{$p$-value } \\
\hline & & & & No BCR & BCR & & \\
\hline rs4965121 & 15 & $\mathrm{G}>\mathrm{C}$ & . & 0.05824 & 0.1152 & $2.106(1.455-3.047)$ & $5.75 \mathrm{E}-05$ \\
\hline rs1128966 & 17 & $\mathrm{C}>\mathrm{G}$ & NT5C3B & 0.1871 & 0.1083 & $0.5278(0.379-0.735)$ & 0.000127 \\
\hline rs 1046404 & 17 & $\mathrm{C}>\mathrm{G}$ & NT5C3B & 0.1871 & 0.1083 & $0.5278(0.379-0.735)$ & 0.000127 \\
\hline rs 1046403 & 17 & $\mathrm{~A}>\mathrm{G}$ & NT5C3B & 0.1871 & 0.1088 & $0.5306(0.381-0.7388)$ & 0.000145 \\
\hline rs781831 & 17 & $\mathrm{~T}>\mathrm{C}$ & ZZEF1 & 0.3565 & 0.2593 & $0.6317(0.4963-0.804)$ & 0.000176 \\
\hline rs 7009549 & 8 & $\mathrm{~A}>\mathrm{G}$ & . & 0.5121 & 0.4124 & $0.6689(0.5379-0.8316)$ & 0.000283 \\
\hline rs12871532 & 13 & $\mathrm{C}>\mathrm{T}$ & . & 0.3663 & 0.2742 & $0.6536(0.5156-0.8285)$ & 0.000417 \\
\hline rs16964211 & 15 & $\mathrm{G}>\mathrm{A}$ & CYP19A1 & 0.2952 & 0.2097 & $0.6335(0.4895-0.82)$ & 0.000489 \\
\hline rs3133745 & 8 & $\mathrm{C}>\mathrm{T}$ & C8orf37-AS1 & 0.2401 & 0.1613 & $0.6088(0.4585-0.8083)$ & 0.000551 \\
\hline rs2071286 & 6 & $\mathrm{G}>\mathrm{A}$ & NOTCH4 & 0.1693 & 0.1019 & $0.5565(0.3955-0.7831)$ & 0.000672 \\
\hline rs10853489 & 18 & $\mathrm{~A}>\mathrm{G}$ & . & 0.4041 & 0.4954 & $1.448(1.166-1.797)$ & 7.73E-04 \\
\hline rs 7439186 & 4 & $\mathrm{C}>\mathrm{T}$ & AMBN & 0.1349 & 0.2005 & $1.607(1.214-2.127)$ & 0.000842 \\
\hline rs 2144425 & 6 & $A>G$ & OR12D3, OR5V1 & 0.3113 & 0.2281 & $0.6539(0.5087-0.8406)$ & 0.000866 \\
\hline rs 3935295 & 1 & $\mathrm{G}>\mathrm{A}$ & PTPN7 & 0.1607 & 0.09677 & $0.5594(0.3948-0.7927)$ & 0.000959 \\
\hline rs4745571 & 9 & $\mathrm{~T}>\mathrm{C}$ & PRUNE2 & 0.1712 & 0.2419 & $1.545(1.192-2.004)$ & 0.000966 \\
\hline rs17168761 & 7 & $\mathrm{~T}>\mathrm{C}$ & AGMO & 0.3623 & 0.2765 & $0.6726(0.5307-0.8523)$ & 0.000987 \\
\hline
\end{tabular}

Abbreviations : SNP: single nucleotide polymorphism; OR: odds ratio; CI : confidence interval; BCR: biochemical recurrence.

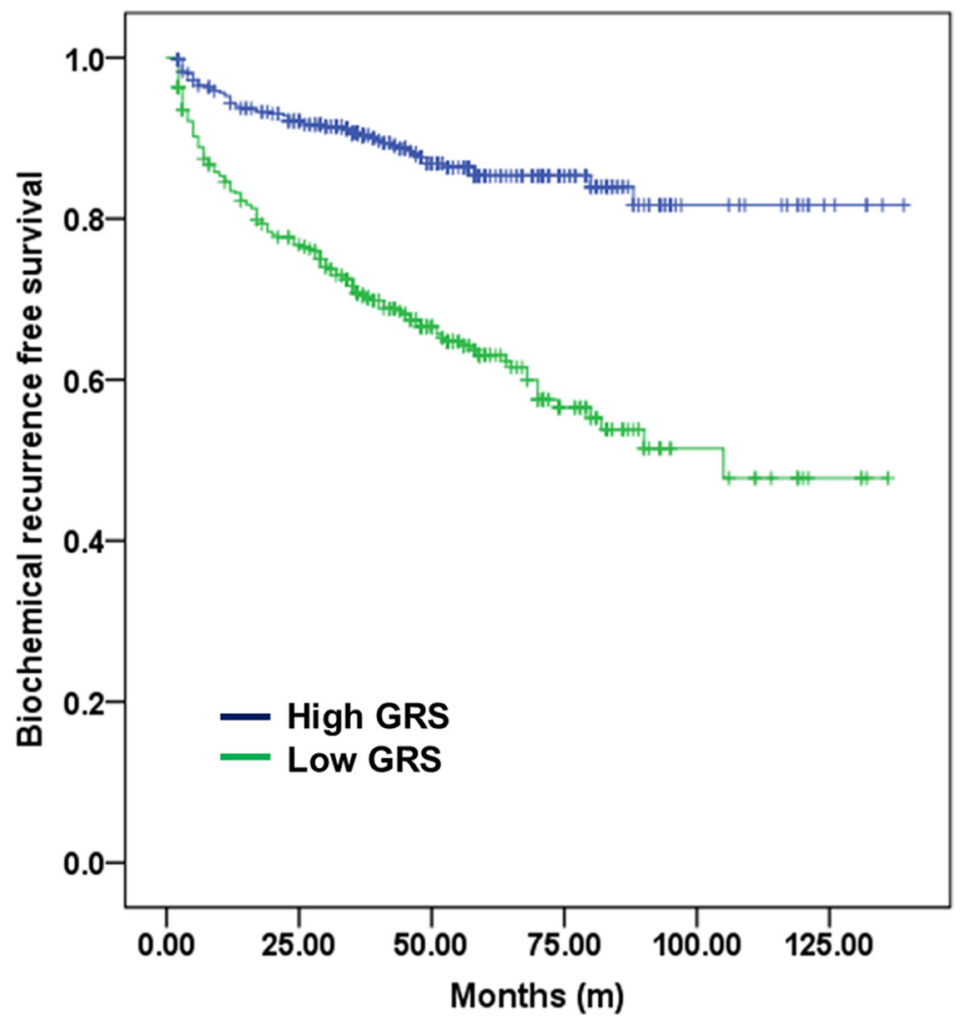

Figure 3: Biochemical recurrence-free survival according to GRS (-2.0) among all patients. The high GRS group had a significantly lower BCR-free survival rate than the low GRS group. The 10-year BCR-free survival rate was $76.5 \%$ vs. $91.2 \%$ among highand low-GRS patients, respectively (log-rank test $p<0.001$ ). 
Table 3: Multivariate Cox proportional models of potential predictors for biochemical recurrence of prostate cancer among men who underwent radical prostatectomy and accuracy analysis of established models according to presence of SNP informations

\begin{tabular}{|c|c|c|c|c|c|c|}
\hline \multirow[b]{2}{*}{ Variables } & \multicolumn{3}{|c|}{ Clinical model } & \multicolumn{3}{|c|}{ Clinico-genetic model } \\
\hline & HR & $95 \% \mathrm{CI}$ & $P$ value & HR & $95 \% \mathrm{CI}$ & $P$ value \\
\hline Age (yrs) & 0.990 & $0.968-1.012$ & 0.375 & 0.990 & $0.968-1.013$ & 0.400 \\
\hline Initial PSA (ng/ml) & 1.003 & $0.999-1.008$ & 0.117 & 0.999 & $0.995-1.003$ & 0.649 \\
\hline Pathologic Gleason score & 2.428 & $1.742-3.385$ & $<0.001$ & 2.600 & $1.878-3.600$ & $<0.001$ \\
\hline Extracapsular extensioin & 3.090 & $2.125-4.493$ & $<0.001$ & 2.847 & $1.956-4.144$ & $<0.001$ \\
\hline Seminal vesicle invasion & 2.637 & $1.869-3.720$ & $<0.001$ & 2.461 & $1.745-3.471$ & $<0.001$ \\
\hline Positive surgical margin & 1.972 & $1.438-2.706$ & $<0.001$ & 2.010 & $1.463-2.762$ & $<0.001$ \\
\hline Genetic risk score & & & & 1.630 & $1.454-1.826$ & $<0.001$ \\
\hline Areas under curve of each multivariate models & \multicolumn{3}{|c|}{0.844} & \multicolumn{3}{|c|}{0.880} \\
\hline
\end{tabular}

Abbreviations: OR: odds ratio; CI: confidence interval; PSA: prostate specific antigen; SNP: single nucleotide polymorphism.

found to be a significant factor after other variables were adjusted (HR: 1.630, 95\% CI: 1.454-1.826, $p<0.001$ ). The accuracy of prediction to BCR was measured $84.4 \%$ in clinical model without GRS, it increased to $88.8 \%$ in clinic-genetic model with GRS (95\% CI, 0.857-0.900; $p=0.0026$ ) (Figure 5).

\section{DISCUSSION}

In this study, we found GRS could be additional predictive biomarker to BCR after RP. Using Exome SNP chips containing a large amount of data, we selected 16 SNPs that significantly affected the BCR after radial surgery

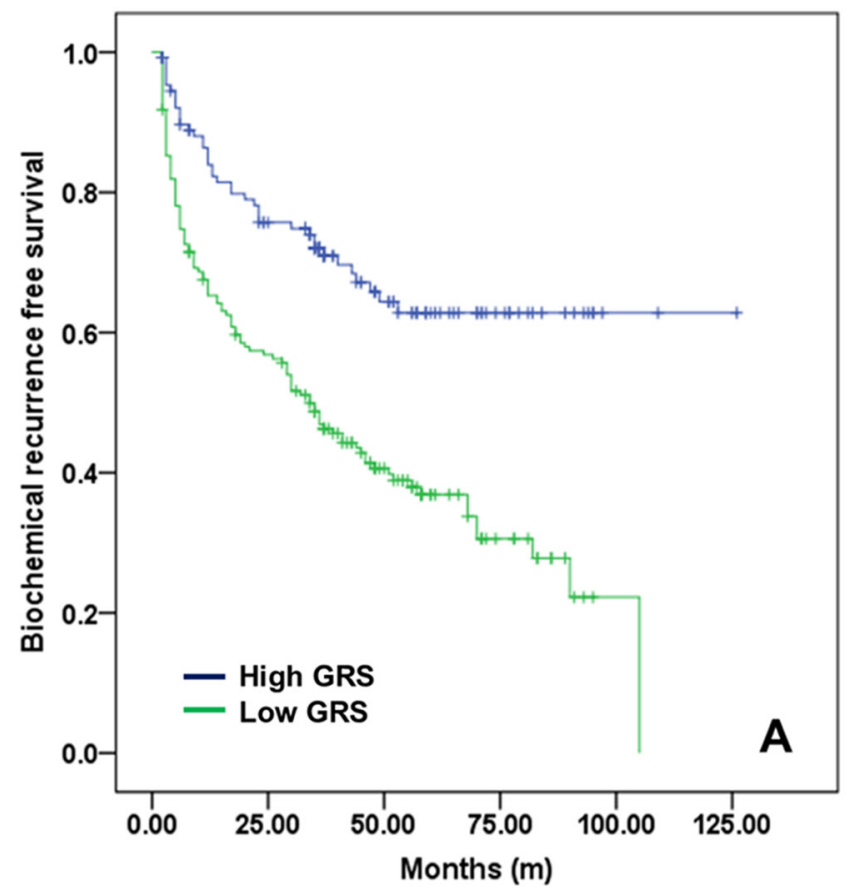

in PCa. The GRS was developed by the sum of each locus multiplied by the weighted risk allele count. Therefore, GRS was a significant factor after adjusting clinical factors. Although patients achieved similar postoperative and pathological outcomes, GRS from blood samples could accurately predict BCR risk after RP among PCa patients.

In general, PCa patients after RP experienced 5 year BCR free survival rate $80 \%, 10$ year BCR free survival rate $68 \%$ [6]. Although high disease free rate, about 35\% of patients had experienced BCR. Among them, about 1/3 patients had radiological recurrence and metastatic disease in 8 years after BCR [21]. Therefore, after definitive therapy as RP, it is important to detect the patients who will

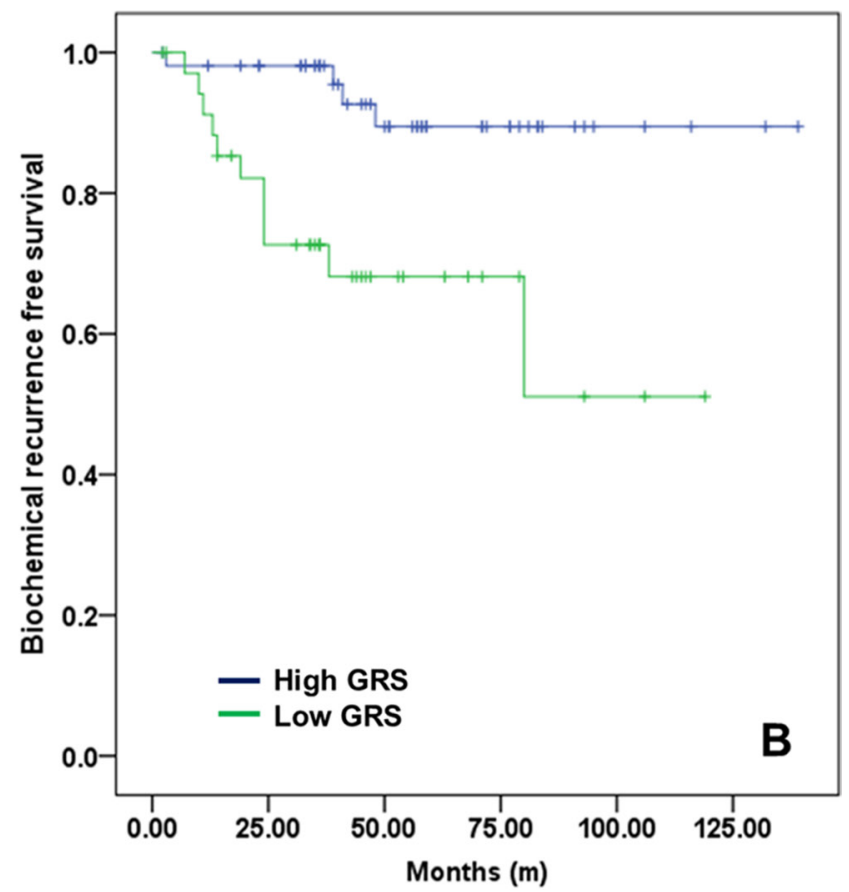

Figure 4: Biochemical recurrence-free survival according to GRS (- 2.0) (A) among pathologic T3 patients and (B) among pathologic T2 margin-positive patients. 
need adjuvant therapy early. According to the American Society for Therapeutic Radiology and Oncology (ASTRO) and the American Urological Association (AUA) guidelines, physicians should offer adjuvant radiotherapy to patients with adverse pathologic findings at the time of RP (i.e., SVI, PSM, ECE) and should offer salvage radiotherapy to those patients [22]. However, adjuvant therapy after RP could be associated with adverse events such as urinary incontinence. Therefore, a more accurate biomarker or prediction model should be used for early detection or prediction of BCR after RP [23].

Recent GWAS results showed numerous SNPs related with PCa susceptibility. Additionally, a few genetic biomarkers have been associated to PCa aggressiveness $[24,25]$. However, the large amount of information from GWAS could not easily be used in clinical situations. Therefore, some simplified calculated methods were introduced. Several customized products such as Oncotype $D^{\circledR}$ (Genomic Health Inc, Redwood City, CA, USA), Prolaris $^{\circledR}$ (Myriad Genetics, Salt Lake City, UT, USA) and Decipher ${ }^{\circledR}$ (GenomeDX Biosciences, Vancouver, $\mathrm{BC}$, Canada) using the polygenic risk score concept are currently available for clinical use [26, 27]. One study showed that the cell-cycle progression (CCP) score using prostatectomy specimens had significant prognostic accuracy after controlling for all available clinical and pathologic data among 413 prostate cancer patients. The hazard ratio (HR) for each unit increase in CCP score (range, -1.62 to 2.16 ) was 2.1 (95\% CI, 1.6 to 2.9 ). With adjustment for Cancer of the Prostate Risk Assessment post-surgical (CAPRA)-score, the HR was 1.7 (95\% CI, 1.3 to 2.4 ). In our study, we constructed a GRS by GWAS analysis using an Exome chip. We found that the HR per unit of GRS was $1.786(95 \%$ CI, $1.604-1.989, p<0.001)$ in univariate analysis and 1.630 (95\% CI, 1.454-1.826, $p<0.001)$ in multivariate methods for prediction of BCR. And another advantage is that our calculated GRS was obtained easily from blood serum.

Several previous studies that combined SNPs and clinical factors to predict PCa outcomes have been published. One study showed 3 SNPs (rs1447295, rs10993994 and rs7920517) were related to BCR in PCa [16]. They adjusted the clinicopathological factors (age, serum PSA, PSM and stage), however they used only 20 SNPs in small 320 patients. Another study also showed precise model for prediction of BCR after RP among 703 patients [28]. They selected 83 SNPs to genotype analysis, and 3 SNPs could be potential marker to predict BCR.

Although these studies showed interesting results to establish more accurate model by adding genetic factors, they also had limitation to relative small patient numbers and genotype field. To overcome these limitations, we prospectively collected many patients and used Exome chip which contained 242,186 SNPs. The action of SNPs to phenotype could be combination of multiple variants, therefore we used GRS to our analysis.

The strengths of our study were as follows: 1) this study was a GWAS-based large-scale study using the HumanExome BeadChip (242,186 SNPs); 2) this study prospectively enrolled patients who underwent RP in a single institution and therefore had similar pathologic analysis by a single pathologist; 3) the GRS was applied to clinical outcome of $\mathrm{PCa}$; 4) a combined clinical-genetic model was created to predict BCR, thereby providing significantly higher accuracy level compared with a model using clinical features alone; and 5) this study was the first

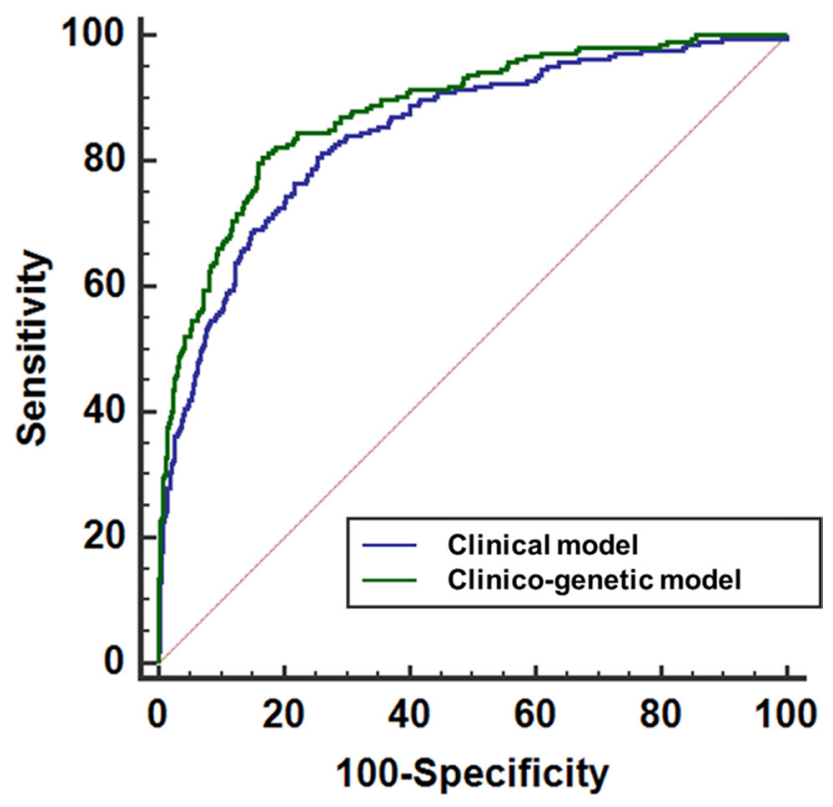

Figure 5: Receiver operating characteristic (ROC) curves of the multivariate logistic regression model devised for biochemical recurrence after radical prostatectomies. The blue line corresponds to a clinical model that excludes the genetic risk score (GRS). The green line corresponds to a combined clinico-genetic model that includes GRS. 
conducted in the Korean population. However, the present study had several limitations as well, including its relative small sample size from the perspective of a GWAS. Although all patients included in this study underwent RP in a single institution, 912 patients was a relatively small number. Another limitation was the lack of cancer-specific and all-cause mortality data. Although this study had an intermediate-term follow-up period (median 51.2 months), the amount of cancer-specific and all-cause mortality was relatively small. Therefore, we excluded these factors from the current analysis. Another limitation was there was no validation cohort to confirm of genomic analysis due to our study had unique cohorts who had genomic data, underwent RP and followed-up for BCR in single institution, we could not find relevant validation cohorts. And we also had limitation which there was no multiple testing validated data. The predictive power of GRS has increased by adding as many variant in model, we used this method. The previous many studies used GRS for clinical application, they had same limitation due to several study barriers $[18,29,30]$. After validation, we can build genetic biomarker to predict survival outcomes by simple blood sampling. Combined with genetic markers and clinical factors, we predict PCa outcome more precisely. Furthermore, we will focus the functional mechanism from genotype to phenotype in near future by molecular work.

In conclusion, we detected 16 SNPs that were significant predictors of BCR by analysis using Exome SNP chips. With that information, we developed a GRSbased tool to predict BCR after RP for prostate cancer. The GRS was an important and significant factor for the prediction of BCR. After combination of clinical factors, the combined clinico-genetic model using GRS had a greater predictive power for BCR.

\section{MATERIALS AND METHODS}

\section{Ethics statement}

After approval of institutional review board (SNUBH Institutional Review Board; B-1312/232-302), our study was performed. And we followed the rule of Declaration of Helsinki. The written informed consents were obtained from all participants.

\section{Study population}

The 1,002 male PCa patients were prospectively included in this study from November 2003 to July 2015. All patients' blood samples were collected prospectively to genotype analysis. We excluded the patients who underwent neo-adjuvant hormonal therapy and/or radiation therapy before RP. The patients whose follow up duration less than 1 year also excluded in this study. After then, total $912 \mathrm{PCa}$ patients were selected in this analysis. All patients had complete clinical records for $\mathrm{PCa}$ including $\mathrm{BCR}$ data.

\section{Pathological evaluation and definition of BCR}

All specimens of biopsy and RP were processed according to the Stanford protocol [31]. Single uropathologist analyzed all specimen. A definition of BCR was two consecutive rises in PSA $>0.2 \mathrm{ng} / \mathrm{ml}$ after RP [32].

\section{Exome genotype and quality control (QC)}

The patients' samples were processed using the Exome chip (HumanExome BeadChip 12v1-1, Illumina, Inc.; San Diego, CA). The $99.706 \%$ markers were successfully genotyped $(242,186 / 242,901)$. The average call rate was calculated $99.987 \%$. Sample quality control was carried out to exclude samples with genotyping rates $<95 \%$, heterozygosity, and cryptic relatedness. Markers were excluded based on the following criteria: 1) monomorphic in our samples, 2) missing call rate $>5 \%, 3$ ) significant deviation from the Hardy-Weinberg equilibrium $\left(P<1.0 \times 10^{-6}\right)$. The 912 subjects remained after quality control was taken forward for subsequent analysis.

\section{SNP analysis methods}

Genotype results were analyzed to calculate OR to BCR using logistic regression methods. We used the previous established methods [33, 34] to measure relationship between genotype and haplotype distributions. The genotype analysis was done by SAS version 9.1 (SAS Inc.; Cary, NC, USA). The multiple testing was also done by common methods [35].

\section{GRS formation}

GRS was calculated by weighted-risk allele count, where risk alleles are weighted by their respective ORs [36-38]. The target 16 SNPs were selected to make GRS using cut off value of $p<0.001$. The natural log (ln) of each OR for each SNP from logistic analysis was multiplied by the number of risk alleles $(2,1$, or 0$)$. GRS was calculated by the sum of the value for each locus.

\section{Statistical analyses}

All 912 patients were divided two groups according to experience of BCR. The clinic-pathological factors were compared with Mann-Whitney test, chi-squared test and Fisher's exact test. The BCR-free survival rate according to GRS (median value) was compared using the log-rank test. Another Kaplan-Meier analysis was performed in subgroup of pathologic T3 patients and pathologic T2R1 patients among controversial patients to adjuvant therapy. We performed the multi-variate Cox proportional hazard analyses to confirm significance to BCR after RP by controlling age, initial PSA, p-stage, Gleason score and PSM. Another multi-variate model adding the GRS also performed, and compared two separate multivariate model 
(with or without GRS) by the methods of rea under the curve (AUC) derived by receiver operating characteristic (Mantel-Haenszel method). The statistical analysis was done by SPSS software package version 21.0 (Statistical Package for Social Sciences ${ }^{\mathrm{TM}}$; Chicago, IL, USA) and Medicalc software version 11 (Mariakerke, Belgium). A two-tailed $p<0.05$ was considered to be significant for all analyses.

\section{ACKNOWLEDGMENTS}

This work was supported by grant no SNUBH-13-2017-006 from the SNUBH (Seoul National University Bundang Hospital) Research Fund and supported by Basic Science Research Program through the National Research Foundation of Korea (NRF) funded by the Ministry of Education (2015R1D1A1A09061013 \& 2014R1A1A2069658).

\section{CONFLICTS OF INTEREST}

The authors have declared no conflicts of interest.

\section{FUNDING}

This work was supported by grant no SNUBH-13-2017-006 from the SNUBH (Seoul National University Bundang Hospital) Research Fund and supported by Basic Science Research Program through the National Research Foundation of Korea (NRF) funded by the Ministry of Education (2015R1D1A1A09061013 \& 2014R1A1A2069658).

\section{REFERENCES}

1. Torre LA, Bray F, Siegel RL, Ferlay J, Lortet-Tieulent J, Jemal A. Global cancer statistics, 2012. CA Cancer J Clin. 2015; 65:87-108.

2. Heidenreich A, Bastian PJ, Bellmunt J, Bolla M, Joniau S, van der Kwast T, Mason M, Matveev V, Wiegel T, Zattoni F, Mottet N, and European Association of Urology. EAU guidelines on prostate cancer. part 1: screening, diagnosis, and local treatment with curative intent-update 2013. Eur Urol. 2014; 65:124-137.

3. Han M, Partin AW, Zahurak M, Piantadosi S, Epstein JI, Walsh PC. Biochemical (prostate specific antigen) recurrence probability following radical prostatectomy for clinically localized prostate cancer. J Urol. 2003; 169:517-523.

4. Caso JR, Tsivian M, Mouraviev V, Polascik TJ, Moul JW. Pathological T2 sub-divisions as a prognostic factor in the biochemical recurrence of prostate cancer. BJU Int. 2010; 106:1623-1627.

5. Freedland SJ, Humphreys EB, Mangold LA, Eisenberger M, Dorey FJ, Walsh PC, Partin AW. Risk of prostate cancerspecific mortality following biochemical recurrence after radical prostatectomy. JAMA. 2005; 294:433-439.
6. Roehl KA, Han M, Ramos CG, Antenor JA, Catalona WJ. Cancer progression and survival rates following anatomical radical retropubic prostatectomy in 3,478 consecutive patients: long-term results. J Urol. 2004; 172:910-914.

7. Kordan Y, Salem S, Chang SS, Clark PE, Cookson MS, Davis R, Herrell SD, Baumgartner R, Phillips S, Smith JA, $\mathrm{Jr}$, Barocas DA. Impact of positive apical surgical margins on likelihood of biochemical recurrence after radical prostatectomy. J Urol. 2009; 182:2695-2701.

8. Eggener SE, Scardino PT, Walsh PC, Han M, Partin AW, Trock BJ, Feng Z, Wood DP, Eastham JA, Yossepowitch O, Rabah DM, Kattan MW, Yu C, et al. Predicting 15year prostate cancer specific mortality after radical prostatectomy. J Urol. 2011; 185:869-875.

9. Kane CJ, Im R, Amling CL, Presti JC Jr, Aronson WJ, Terris MK, Freedland SJ, and SEARCH Database Study Group. Outcomes after radical prostatectomy among men who are candidates for active surveillance: results from the SEARCH database. Urology. 2010; 76:695-700.

10. Gu CY, Qin XJ, Qu YY, Zhu Y, Wan FN, Zhang GM, Sun LJ, Zhu Y, Ye DW. Genetic variants of the CYP1B1 gene as predictors of biochemical recurrence after radical prostatectomy in localized prostate cancer patients. Medicine (Baltimore). 2016; 95:e4066.

11. Al Olama AA, Kote-Jarai Z, Berndt SI, Conti DV, Schumacher F, Han Y, Benlloch S, Hazelett DJ, Wang Z, Saunders E, Leongamornlert D. A meta-analysis of 87,040 individuals identifies 23 new susceptibility loci for prostate cancer. Nat Genet. 2014; 46:1103-9.

12. Panagiotou OA, Travis RC, Campa D, Berndt SI, Lindstrom S, Kraft P, Schumacher FR, Siddiq A, Papatheodorou SI, Stanford JL, Albanes D, Virtamo J, Weinstein SJ, et al, and PRACTICAL Consortium. A genome-wide pleiotropy scan for prostate cancer risk. Eur Urol. 2015; 67:649-657.

13. Amin Al Olama A, Kote-Jarai Z, Schumacher FR, Wiklund F, Berndt SI, Benlloch S, Giles GG, Severi G, Neal DE, Hamdy FC, Donovan JL, Hunter DJ, Henderson BE, et al, and UK Genetic Prostate Cancer Study Collaborators/ British Association of Urological Surgeons' Section of Oncology, and UK ProtecT Study Collaborators, and Australian Prostate Cancer Bioresource, and PRACTICAL Consortium. A meta-analysis of genome-wide association studies to identify prostate cancer susceptibility loci associated with aggressive and non-aggressive disease. Hum Mol Genet. 2013; 22:408-415.

14. Oh JJ, Park S, Lee SE, Hong SK, Lee S, Lee HM, Lee JK, Ho JN, Yoon S, Byun SS. Genome-wide detection of allelic genetic variation to predict biochemical recurrence after radical prostatectomy among prostate cancer patients using an exome SNP chip. J Cancer Res Clin Oncol. 2015; 141:1493-1501.

15. Xu J, Mo Z, Ye D, Wang M, Liu F, Jin G, Xu C, Wang X, Shao Q, Chen Z, Tao Z, Qi J, Zhou F, et al. Genomewide association study in Chinese men identifies two new prostate cancer risk loci at 9q31.2 and 19q13.4. Nat Genet. 2012; 44:1231-1235. 
16. Huang SP, Huang LC, Ting WC, Chen LM, Chang TY, Lu TL, Lan YH, Liu CC, Yang WH, Lee HZ, Hsieh CJ, Bao BY. Prognostic significance of prostate cancer susceptibility variants on prostate-specific antigen recurrence after radical prostatectomy. Cancer Epidemiol Biomarkers Prev. 2009; 18:3068-3074.

17. Conran CA, Na R, Chen H, Jiang D, Lin X, Zheng SL, Brendler CB, Xu J. Population-standardized genetic risk score: the SNP-based method of choice for inherited risk assessment of prostate cancer. Asian J Androl. 2016; 18:520-524.

18. Aly $\mathrm{M}$, Wiklund $\mathrm{F}$, Xu J, Isaacs WB, Eklund $\mathrm{M}$, D’Amato M, Adolfsson J, Gronberg H. Polygenic risk score improves prostate cancer risk prediction: results from the Stockholm-1 cohort study. Eur Urol. 2011; 60:21-28.

19. Kader AK, Sun J, Reck BH, Newcombe PJ, Kim ST, Hsu FC, D'Agostino RB Jr, Tao S, Zhang Z, Turner AR, Platek GT, Spraggs CF, Whittaker JC, et al. Potential impact of adding genetic markers to clinical parameters in predicting prostate biopsy outcomes in men following an initial negative biopsy: findings from the REDUCE trial. Eur Urol. 2012; 62:953-961.

20. Zhu Y, Han CT, Chen HT, Liu F, Zhang GM, Yang WY, $\mathrm{Xu}$ JF, Ye DW. Influence of age on predictiveness of genetic risk score for prostate cancer in a Chinese hospital-based biopsy cohort. Oncotarget. 2015; 6:22978-22984. https:// doi.org/10.18632/oncotarget.3938.

21. Pound CR, Partin AW, Eisenberger MA, Chan DW, Pearson JD, Walsh PC. Natural history of progression after PSA elevation following radical prostatectomy. JAMA. 1999; 281:1591-1597.

22. Thompson IM, Valicenti RK, Albertsen P, Davis BJ, Goldenberg SL, Hahn C, Klein E, Michalski J, Roach M, Sartor O, Wolf JS Jr, Faraday MM. Adjuvant and salvage radiotherapy after prostatectomy: AUA/ASTRO Guideline. J Urol. 2013; 190:441-449.

23. Bruce JY, Lang JM, McNeel DG, Liu G. Current controversies in the management of biochemical failure in prostate cancer. Clin Adv Hematol Oncol. 2012; 10:716-722.

24. Ahn J, Kibel AS, Park JY, Rebbeck TR, Rennert H, Stanford JL, Ostrander EA, Chanock S, Wang MH, Mittal RD, Isaacs WB, Platz EA, Hayes RB. Prostate cancer predisposition loci and risk of metastatic disease and prostate cancer recurrence. Clin Cancer Res. 2011; 17:1075-1081.

25. Bensen JT, Xu Z, Smith GJ, Mohler JL, Fontham ET, Taylor JA. Genetic polymorphism and prostate cancer aggressiveness: a case-only study of 1,536 GWAS and candidate SNPs in African-Americans and EuropeanAmericans. Prostate. 2013; 73:11-22.

26. Klein EA, Cooperberg MR, Magi-Galluzzi C, Simko JP, Falzarano SM, Maddala T, Chan JM, Li J, Cowan JE, Tsiatis AC, Cherbavaz DB, Pelham RJ, TenggaraHunter I, et al. A 17-gene assay to predict prostate cancer aggressiveness in the context of Gleason grade heterogeneity, tumor multifocality, and biopsy undersampling. Eur Urol. $2014 ; 66: 550-560$.
27. Klein EA, Haddad Z, Yousefi K, Lam LL, Wang Q, Choeurng V, Palmer-Aronsten B, Buerki C, Davicioni E, Li J, Kattan MW, Stephenson AJ, Magi-Galluzzi C. Decipher Genomic Classifier Measured on Prostate Biopsy Predicts Metastasis Risk. Urology. 2016; 90:148-152.

28. Morote J, Del Amo J, Borque A, Ars E, Hernandez C, Herranz F, Arruza A, Llarena R, Planas J, Viso MJ, Palou J, Raventos CX, Tejedor D, et al. Improved prediction of biochemical recurrence after radical prostatectomy by genetic polymorphisms. J Urol. 2010; 184:506-511.

29. Nordstrom T, Aly M, Eklund M, Egevad L, Gronberg H. A genetic score can identify men at high risk for prostate cancer among men with prostate-specific antigen of 1-3 ng/ ml. Eur Urol. 2014; 65:1184-1190.

30. Chen H, Liu X, Brendler CB, Ankerst DP, Leach RJ, Goodman PJ, Lucia MS, Tangen CM, Wang L, Hsu FC, Sun J, Kader AK, Isaacs WB, et al. Adding genetic risk score to family history identifies twice as many high-risk men for prostate cancer: Results from the prostate cancer prevention trial. Prostate. 2016; 76:1120-1129.

31. McNeal JE, Redwine EA, Freiha FS, Stamey TA. Zonal distribution of prostatic adenocarcinoma. Correlation with histologic pattern and direction of spread. Am J Surg Pathol. 1988; 12:897-906.

32. Cookson MS, Aus G, Burnett AL, Canby-Hagino ED, D'Amico AV, Dmochowski RR, Eton DT, Forman JD, Goldenberg SL, Hernandez J, Higano CS, Kraus SR, Moul JW, et al. Variation in the definition of biochemical recurrence in patients treated for localized prostate cancer: the American Urological Association Prostate Guidelines for Localized Prostate Cancer Update Panel report and recommendations for a standard in the reporting of surgical outcomes. J Urol. 2007; 177:540-545.

33. Hedrick PW. Gametic disequilibrium measures: proceed with caution. Genetics. 1987; 117:331-341.

34. Stephens M, Smith NJ, Donnelly P. A new statistical method for haplotype reconstruction from population data. Am J Hum Genet. 2001; 68:978-989.

35. Nyholt DR. A simple correction for multiple testing for single-nucleotide polymorphisms in linkage disequilibrium with each other. Am J Hum Genet. 2004; 74:765-769.

36. Szulkin R, Whitington T, Eklund M, Aly M, Eeles RA, Easton D, Kote-Jarai ZS, Amin Al Olama A, Benlloch S, Muir K, Giles GG, Southey MC, Fitzgerald LM, et al, and Australian Prostate Cancer BioResource, and Practical Consortium. Prediction of individual genetic risk to prostate cancer using a polygenic score. Prostate. 2015; 75: 1467-1474.

37. Amin Al Olama A, Benlloch S, Antoniou AC, Giles GG, Severi G, Neal DE, Hamdy FC, Donovan JL, Muir K, Schleutker J, Henderson BE, Haiman CA, Schumacher FR, et al, and UK Genetic Prostate Cancer Study Collaborators/ British Association of Urological Surgeons' Section of Oncology, and UK ProtecT Study Collaborators, and PRACTICAL Consortium. Risk Analysis of Prostate 
Cancer in PRACTICAL, a Multinational Consortium, Using 25 Known Prostate Cancer Susceptibility Loci. Cancer Epidemiol Biomarkers Prev. 2015; 24:1121-1129.
38. Pashayan N, Duffy SW, Neal DE. Implications of polygenic risk-stratified screening for prostate cancer on overdiagnosis. Genet Med. 2015; 17:789-95. 